\title{
Revealing the Intrinsic Peroxidase-Like Catalytic Mechanism of Heterogeneous Single-Atom Co-MoS
}

Cite as

Nano-Micro Lett.

(2019) 11:102

Received: 26 July 2019

Accepted: 5 October 2019

Published online: 22 November 2019

(C) The Author(s) 2019
Ying Wang ${ }^{1}$, Kun $\mathrm{Qi}^{1,2}$, Shansheng $\mathrm{Yu}^{1}$, Guangri Jia ${ }^{1}$, Zhiliang Cheng ${ }^{4}$, Lirong Zheng ${ }^{5}$, Qiong $\mathrm{Wu}^{1}$, Qiaoliang $\mathrm{Bao}^{2}$, Qingqing Wang ${ }^{6}$, Jingxiang $\mathrm{Zhao}^{3 凶}$, Xiaoqiang Cui ${ }^{1}$, Weitao Zheng ${ }^{1}$

Ying Wang and Kun Qi contributed equally to this work.

$\triangle$ Jingxiang Zhao, xjz_hmily@163.com; Xiaoqiang Cui, xqcui@jlu.edu.cn

1 Key Laboratory of Automobile Materials of MOE, School of Materials Science and Engineering, Jilin University, 2699 Qianjin Street, Changchun 130012, People's Republic of China

2 Department of Materials Science and Engineering, ARC Centre of Excellence in Future Low-Energy Electronics Technologies (FLEET), Monash University, Clayton, VIC 3800, Australia

3 Key Laboratory of Photonic and Electronic Bandgap Materials, Ministry of Education, College of Chemistry and Chemical Engineering, Harbin Normal University, Harbin 150025, People's Republic of China

4 Department of Bioengineering, University of Pennsylvania, 210 South 33rd Street, 240 Skirkanich Hall, Philadelphia, PA 19104, USA

5 Beijing Synchrotron Radiation Facility, Institute of High Energy Physics, Chinese Academy of Sciences, Beijing 100190, People's Republic of China

6 School of Chemistry and Chemical Engineering, MOE Key Laboratory of Micro-System and Micro-Structure Manufacturing, Harbin Institute of Technology, Harbin 150001, People's Republic of China

\section{HIGHLIGHTS}

- Single-atom $\mathrm{Co}-\mathrm{MoS}_{2}\left(\mathrm{SA} \mathrm{Co}-\mathrm{MoS}_{2}\right)$ is prepared successfully to serve as a proof-of-concept nanozyme model, which exhibits peroxidase-like performance comparable to that of natural enzymes.

- The different mechanisms between the single-atom metal center and the support are investigated experimentally and theoretically.

ABSTRACT The single-atom nanozyme is a new concept and has tremendous prospects to become a next-generation nanozyme. However, few studies have been carried out to elucidate the intrinsic mechanisms for both the single atoms and the supports in single-atom nanozymes. Herein, the heterogeneous single-atom $\mathrm{Co}-\mathrm{MoS}_{2}(\mathrm{SA} \mathrm{Co}-$ $\mathrm{MoS}_{2}$ ) is demonstrated to have excellent potential as a high-performance peroxidase mimic. Because of the well-defined structure of SA Co- $\mathrm{MoS}_{2}$, its peroxidase-like mechanism is extensively interpreted through experimental and theoretical studies. Due to the different adsorption energies of substrates on different parts of SA Co- $\mathrm{MoS}_{2}$ in the peroxidase-like reaction, SA Co favors electron transfer mechanisms, while $\mathrm{MoS}_{2}$ relies on Fenton-like reactions. The different catalytic pathways provide an intrinsic

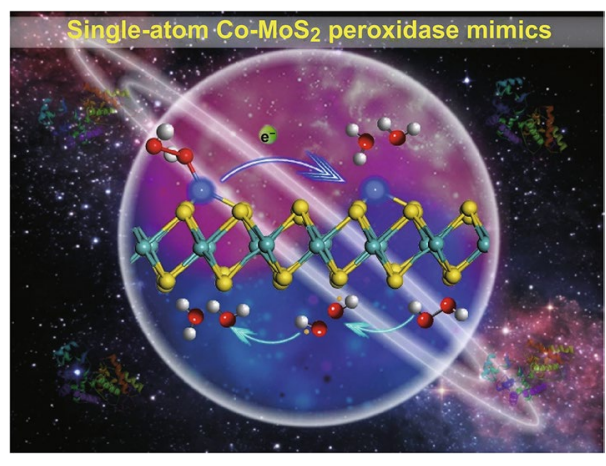
understanding of the remarkable performance of SA Co-MoS 2 . The present study not only develops a new kind of single-atom catalyst (SAC) as an elegant platform for understanding the enzyme-like activities of heterogeneous nanomaterials but also facilitates the novel application of SACs in biocatalysis.

KEYWORDS Biocatalysis; Nanozymes; Peroxidase mimic; Reaction mechanisms; Single-atom catalysts 


\section{Introduction}

The high extraction cost and low stability of natural enzymes caused by denaturation and deactivation hinder their practical applications [1]. Nanomaterials with enzyme-like characteristics (nanozymes) have become promising alternatives to traditional enzymes and have the unique advantage of bridging nanotechnology and biology [2,3]. Many types of nanozymes have been reported and applied in the catalysis of a broad range of reactions [4-6]. However, the activity and specificity of nanozymes still differ substantially from those of natural enzymes. There is an urgent need to obtain a deep understanding of the intrinsic catalytic mechanisms and kinetics to design and develop more efficient enzyme mimic systems, but meeting this need remains a significant challenge [7].

The atomistic-level exploration of the original active sites of nanozymes is mainly performed by simplifying the singlecomponent catalysts of noble metal nanoparticles [8-10], transition metal oxides [11], and carbon-based materials [12, 13]. The cascade reactions catalyzed by multiple enzymes in an organism provide great impetus for preparing composite catalysts by integrating different kinds of nanozymes to mimic the complexity of biocatalysis $[14,15]$. Moreover, natural horse radish peroxidase is composed of a heme group and two calcium atoms, and the integrity of this complex protein is crucial for the high selectivity and efficiency of the natural homogeneous enzyme [16]. However, the structure of heterogeneous nanozymes is too inhomogeneous to achieve satisfactory enzyme-like activity and selectivity. In addition, the internal relationship between homogeneous molecular enzymes and heterogeneous nanozymes is still poorly understood and poses a challenge for achieving an indepth understanding of enzyme-like catalytic mechanisms. Single-atom catalysts (SACs), which act as a bridge between homogeneous and heterogeneous catalysis, not only offer a simple ideal model for the design of rational nanozymes at the atomic level but also provide an appropriate platform for studying the origins of enzyme-like activities thanks to their advantages of homogeneous active sites and single atoms in low-coordination environments [17-19]. However, studies on single-atom nanozymes are confined to only singleatomically dispersed metal- $\mathrm{N}_{x}$ on a carbon support (M-N-C) [20-25]. Further systematic studies are required to develop more kinds of heterogeneous single-atom catalysts and deeply investigate the enzyme-like catalytic mechanisms for both the single atoms and the supports.

Herein, we chose single-atom Co- $-\mathrm{MoS}_{2}\left(\mathrm{SA} \mathrm{Co}-\mathrm{MoS}_{2}\right)$ as a proof-of-concept nanozyme for examination of a highperformance peroxidase-like reaction. Through experiments and calculations, we explored in detail how the introduction of SA Co affected the peroxidase-like activity, substrate affinity, and corresponding reaction energies. The results of these studies facilitated the identification of the different catalytic sites in the hybrid SA Co- $\mathrm{MoS}_{2}$ catalyst and the reaction mechanism. This research may enhance the knowledge on the intrinsic properties of enzyme-like activities and pave the way for the rational design of highly effective nanozymes.

\section{Experimental Section}

\subsection{Chemicals and Materials}

All chemicals were used as received without further purification. $\mathrm{H}_{2} \mathrm{O}_{2}$ (30 wt\%), 3,3',5,5'-tetramethylbenzidine (TMB), o-phenylenediamine (OPD), 2,2'-azinobis(3-ethylbenzthiazoline-6-sulfonate) (ABTS), horse radish peroxidase (HRP), phosphate-buffered saline (PBS) (0.1 M), $D$-(+)-glucose, terephthalic acid (TA), uric acid (UA), $L$-ascorbic acid (AA), dopamine hydrochloride (DA), cytochrome $c$ (Cyt $c, \geq 95 \%$ ), trioctylphosphine oxide (TOPO, $\mathrm{C}_{24} \mathrm{H}_{51} \mathrm{OP}, 90 \%$ ), anhydrous $o$-dichloride benzene (DCB, $\left.\mathrm{C}_{14} \mathrm{H}_{10} \mathrm{Cl}_{2} \mathrm{~N}_{2}\right)$, and cobalt carbonyl $\left(\mathrm{Co}_{2}(\mathrm{CO})_{8}\right.$, Co content $\geq 90 \%$ ) were obtained from Sigma-Aldrich (USA). Nafion-ethanol solution was purchased from Adamas-beta Chemical Co., (Switzerland). Ammonium heptamolybdate tetrahydrate $\left(\left(\mathrm{NH}_{4}\right)_{6} \mathrm{Mo}_{7} \mathrm{O}_{24} \cdot 4 \mathrm{H}_{2} \mathrm{O}, \mathrm{AR}\right)$, thiourea $\left(\mathrm{CH}_{4} \mathrm{~N}_{2} \mathrm{~S}\right.$, $\mathrm{AR}), n$-hexane $\left(\mathrm{C}_{6} \mathrm{H}_{14}, \mathrm{AR}\right)$, potassium thiocyanate (KSCN, $\mathrm{AR})$, sodium acetate (NaAc, $\mathrm{AR})$, sodium chloride $(\mathrm{NaCl})$, fructose, lactose, xylose, L-cysteine, mannose, sucrose, urea, serine, arginine, cysteine, acetic acid (HAc, AR), ethanol $\left(\mathrm{CH}_{3} \mathrm{CH}_{2} \mathrm{OH}, \mathrm{AR}\right)$, and dimethyl sulfoxide (DMSO) were purchased from Sinopharm Chemical Reagent (China). Oleylamine (OA, $\left.\mathrm{C}_{18} \mathrm{H}_{37} \mathrm{~N}, 80-90 \%\right)$ was purchased from Acros Organics, USA. Argon (Ar, ultra-purity) was obtained from Xin' guang Gas Co., China. Carbon fiber paper was purchased from AvCarb, USA. Deionized water from a Milli-Q system $\left(18.2 \mathrm{M} \Omega \mathrm{cm}\right.$ at $\left.25{ }^{\circ} \mathrm{C}\right)$ was used throughout the experiments. 


\subsection{Characterization}

Transmission electron microscopy (TEM), high-resolution transmission electron microscopy (HRTEM), and energydispersive X-ray (EDX) spectroscopy were performed on an FEI Tecnai G2 F20 transmission electron microscope operated at $200 \mathrm{kV}$. The samples were prepared by dropping ethanol dispersions of the samples onto 300-mesh carbon-coated copper grids and then evaporating the solvent. HRTEM images were acquired using a JEOL-ARM200F transmission electron microscope operated at $200 \mathrm{kV}$. The attainable spatial resolution of the microscope was $78 \mathrm{pm}$ with a probe spherical aberration corrector. High-angle annular dark field (HAADF) images were acquired with an illumination semi-angle of $25 \mathrm{mrad}$ and probe current of $100 \mathrm{pA}$. The dwell time for image acquisition was set at $10 \mu$ s per pixel to ensure the desirable signal-to-noise ratio. The collection angles for the HAADF images were fixed at 90-250 mrad. To obtain high-quality STEM images with atomic resolution, $\mathrm{SA} \mathrm{Co}-\mathrm{MoS}_{2}$ was pre-treated at $80^{\circ} \mathrm{C}$ in a vacuum oven for $4 \mathrm{~h}$ to remove any organic ligands from its surface. X-ray photoelectron spectroscopy (XPS) measurements were performed with an ESCALAB-250 instrument (Thermo Fisher Scientific, USA) using a monochromatic $\mathrm{Al}-\mathrm{K} \alpha(14,866 \mathrm{eV})$ radiation source and a hemisphere detector with an energy resolution of $0.1 \mathrm{eV}$. Peak positions were corrected by the $\mathrm{C} 1 \mathrm{~s}$ spectrum at $284.6 \mathrm{eV}$. Co K-edge X-ray absorption spectra were obtained at Beijing Synchrotron Facility (BSRF) on beamline 1 W1B (XAFS station) at $2.2 \mathrm{GeV}$ in fluorescence mode. The EXAFS raw data were processed using the ATHENA module implemented in the IFEFFIT software packages according to the standard procedures of the background-subtracted, normalized and Fourier transformed. The Raman spectra were obtained by a Renishaw 1000 spectrometer with an excitation laser line of $532 \mathrm{~nm}$. Typical UV-Vis spectra were acquired with a UV-2550 spectrometer (Shimazu Co., Japan). Fluorescence (PL) spectra were obtained using an LS55 spectrometer (PerkinElmer Inc., USA). Electrochemical tests were carried out on a CHI 650D electrochemical workstation (Shanghai, Chenhua Co., China). Optical photographs were acquired using an iPhone $6 \mathrm{~s}$.

$\mathrm{MoS}_{2}$ was synthesized according to the reported procedure [26]. $24.7 \mathrm{mg}$ of hexaammonium heptamolybdate tetrahydrate and $53.2 \mathrm{mg}$ of thiourea were dissolved in $20 \mathrm{~mL}$ of deionized water under vigorous stirring. Then, the solution was transferred into a $30 \mathrm{~mL}$ Teflon-lined stainless steel autoclave and maintained at $220^{\circ} \mathrm{C}$ for $18 \mathrm{~h}$ before the reaction system was allowed to cool down to room temperature. The final product was washed several times with water and ethanol to remove any possible ions and finally suspended in ethanol.

Co nanodisks (NDs) were synthesized using standard air-free procedures [27]. $0.1 \mathrm{~g}$ of TOPO was degassed with argon for $20 \mathrm{~min}$ in a three-neck flask, following by the introduction of $0.1 \mathrm{~mL}$ of OA and $15 \mathrm{~mL}$ of DCB under argon, then the regents were heating to reflux $\left(182{ }^{\circ} \mathrm{C}\right)$ and rapidly injecting $0.54 \mathrm{~g}$ of $\mathrm{Co}_{2}(\mathrm{CO})_{8}$ containing $1-5 \%$ hexane diluted in $3 \mathrm{~mL}$ of DCB (precursor solution). $10 \mathrm{~min}$ later, the reaction was stopped by quenching in an ice water bath. The final products were processed by extracting the solution, washing several times with water and methanol to remove the possible ions and organic component, and finally suspending in argon-saturated water for storage.

\subsection{Preparation of SA Co- $-\mathrm{MoS}_{2}$ Catalysts}

Assembly of Co NDs onto $\mathrm{MoS}_{2}$ [28]. Co NDs were assembled on $\mathrm{MoS}_{2}$ nanosheets by mixing the two solutions in a $20 \mathrm{~mL}$ conical flask with certain mass ratio and following by 20 min degassing with argon. The mixture solution was ultrasonicated for $24 \mathrm{~h}(800 \mathrm{~W}$ at $40 \mathrm{KHz})$ while keeping at $4{ }^{\circ} \mathrm{C}$ in a thermostat system. The product was centrifuged and washed for three times with water, and finally stored as argon-saturated water suspension.

The working electrode was prepared by drop casting Co $\mathrm{ND} / \mathrm{MoS}_{2}$ onto the carbon fibre paper. The electrochemical leaching was performed by cyclic voltammetry scanning between $0.1 \mathrm{~V}$ to $-0.4 \mathrm{~V}$ in a $0.5 \mathrm{M} \mathrm{H}_{2} \mathrm{SO}_{4}$ solution for 50 cycles. The final SA Co-MoS $\mathrm{S}_{2}$ was obtained by sonicating the electrode in an ethanol solution for $30 \mathrm{~min}$ and then collecting the sedimentation after $6 \mathrm{~h}$. The whole leaching process was repeated twice to ensure the entirely removing of Co nanodisks.

\subsection{Peroxidase-Like Activity of SA Co-MoS}

The working stock solution of $5.0 \mathrm{M} \mathrm{H}_{2} \mathrm{O}_{2}$ was prepared by diluting $\mathrm{H}_{2} \mathrm{O}_{2}$ (30 wt $\%$ ), and solutions of different concentrations were prepared by sequential dilution of the stock solution. The peroxidase-like activity of SA Co- $-\mathrm{MoS}_{2}$ 
was examined in the oxidation of TMB, ABTS, and OPD, which produced colorimetric changes with different typical UV-Vis absorbance peaks. The reactions were carried out as follows: $8 \mu \mathrm{L}$ of SA Co- $\mathrm{MoS}_{2}$ catalyst $\left(1.25 \mathrm{mg} \mathrm{mL}^{-1}\right)$, $16 \mu \mathrm{L}$ of TMB $(10 \mathrm{mM})$, and $326 \mu \mathrm{L}$ of acetate buffer $(0.20 \mathrm{mM}, \mathrm{pH}=4.0)$ were mixed. Then, $50 \mu \mathrm{L}$ of a $\mathrm{H}_{2} \mathrm{O}_{2}$ solution of different concentrations was added to keep the total volume at $400 \mu \mathrm{L}$. Finally, the mixture was further incubated at $45{ }^{\circ} \mathrm{C}$ for $20 \mathrm{~min}$, and a blue color with major absorbance peaks at 370 and $652 \mathrm{~nm}$ was produced.

\subsection{OH Radical and Dissolved $\mathrm{O}_{2}$ Measurement}

The fluorescence spectra were obtained under the following conditions: $50 \mathrm{mM} \mathrm{H}_{2} \mathrm{O}_{2}, 1 \mathrm{mM}$ terephthalic acid (TA), and different concentrations of the SA Co- $\mathrm{MoS}_{2}$ catalyst were first incubated in $0.1 \mathrm{M} \mathrm{HAc-NaAc}$ buffer $(\mathrm{pH}=5.0)$ at $40{ }^{\circ} \mathrm{C}$ for $8 \mathrm{~h}$, and then the catalysts were then removed from the reaction solution by centrifugation. The final solutions were used for fluorometric measurements.

\subsection{Apparent Kinetic Analysis}

Steady-state kinetic assays of the TMB/ $\mathrm{H}_{2} \mathrm{O}_{2} / \mathrm{SA}$ Co- $-\mathrm{MoS}_{2}$ reaction system were performed by recording the absorption spectrum at selected time intervals in scanning kinetic mode in the above optimized conditions [29]. The TMB concentration was determined from its oxidation products and absorbance values monitored at $652 \mathrm{~nm}$, which were converted by the Beer-Lambert Law as follows: $A=\varepsilon b c$, where the molar absorption coefficient $\varepsilon$ was $39,000 \mathrm{M}^{-1} \mathrm{~cm}^{-1}$ and the path length $b$ of the glass cuvette was $0.1 \mathrm{~cm}$. For TMB and $\mathrm{H}_{2} \mathrm{O}_{2}$ as substrates, the apparent kinetic parameters were fitted based on the double-reciprocal plot derived from the Michaelis-Menten equation as follows: $1 / v=\left(K_{\mathrm{m}} / V_{\max }\right) \times(1 /[S])+1 / V_{\max }$, where $\nu$ is the reaction initial velocity, $V_{\max }$ is the maximal reaction velocity, $[S]$ is the concentration of the substrate, and $K_{\mathrm{m}}$ is the Michaelis-Menten constant.

\subsection{Preparation of $\mathrm{SA} \mathrm{Co-MoS} / \mathrm{GCE}$}

Before modification of a glassy carbon electrode (GCE, $d=3 \mathrm{~mm}$ ), the bare GCE was carefully polished with emery paper and chamois leather containing 1.0, 0.3, and $0.05 \mu \mathrm{m}$ alumina slurries to obtain a mirror-like surface and then sequentially rinsed with acetone, ethanol, and ultrapure water in an ultrasonic bath. After polishing, the electrode was immersed in $0.50 \mathrm{M} \mathrm{H}_{2} \mathrm{SO}_{4}$ for activation by 10 cycles between -0.20 and $0.60 \mathrm{~V}$ with a scan rate of $50 \mathrm{mV} \mathrm{s}^{-1}$ until a steady profile was obtained. After the electrode was dried under a nitrogen flow, $5 \mu \mathrm{L}$ of a dispersion of SA Co- $\mathrm{MoS}_{2}$ or $\mathrm{MoS}_{2}$ was coated on the surface of the electrode and dried under ambient conditions. The doses of the SA Co- $-\mathrm{MoS}_{2}$ and $\mathrm{MoS}_{2}$ catalysts were kept constant according to the amount of Mo (17.6 $\mu \mathrm{g} \mathrm{cm}^{-2}$ for Mo) determined by inductively coupled plasma mass spectrometry (ICP-MS). Then, $6 \mu \mathrm{L}$ of a Nafion - ethanol solution $(0.05 \mathrm{wt} \%)$ was pipetted onto the electrode surface.

\subsection{Electrochemical Measurements}

PBS buffer $(\mathrm{pH}=7.4)$ was bubbled with high-purity nitrogen for at least $10 \mathrm{~min}$ to deoxygenate it prior to each test. Electrochemical measurements were carried on a computer-controlled CHI650D electrochemical workstation with a standard threeelectrode system at room temperature. A bare GCE or various modified GCEs served as the working electrode (WE). A platinum foil electrode $(1 \mathrm{~cm} \times 1 \mathrm{~cm})$ was used as the counter electrode, and a saturated calomel electrode ( $\mathrm{SCE}, \mathrm{Hg} / \mathrm{HgCl}_{2}$ in saturated $\mathrm{KCl}$ ) was used as the reference electrode. Before adding $\mathrm{H}_{2} \mathrm{O}_{2}$, all modified GCEs were cleaned by cyclic voltammetric $(\mathrm{CV})$ sweeping from -0.7 to $0.7 \mathrm{~V}$ at $50 \mathrm{mV} \mathrm{s}^{-1}$ in electrolyte for 40 cycles.

\subsection{DFT Calculations}

Our spin-polarized DFT computations were performed by using the $\mathrm{DMol}^{3}$ code $[30,31]$. The electron interactions were described by Perdew-Burke-Ernzerhof (PBE) exchange-correlation functional within the generalized gradient approximation (GGA) [32] The empirical correction in Grimme's scheme (i.e., DFT + D2) was utilized to treat the (possible) van der Waals interactions [33] The relativistic effects of transition metals were considered through the density functional semi-core pseudopotential (DSPP) [34], in which a single effective potential and some degree of relativistic corrections replace the core electrons, while the double numerical plus polarization (DNP) basis set was used for other elements. Self-consistent field (SCF) computations 
were performed with a convergence criterion of $10^{-6}$ a.u. on the total energy and electronic computations. To ensure high-quality results, the real-space global orbital cutoff radius was chosen as high as $5.2 \AA$ in all the computations. The Brilliouin zone was sampled with a Monkhorst-Pack mesh with a $5 \times 5 \times 1$ grid in reciprocal space during geometry optimizations. The $1 \mathrm{~T}$ - and $2 \mathrm{H}-\mathrm{MoS}_{2}$ nanosheets were built using a $4 \times 4$ supercell containing $16 \mathrm{Mo}$ and 32 $\mathrm{S}$ atoms. The vacuum space was set to $20 \AA$, which was enough to avoid the interactions between periodic images.

The Gibbs free energy change $(\Delta G)$ of every elemental step was determined by the following equation: $\Delta G=\Delta E+\Delta Z P E-T \Delta S$. The reaction energy $(\Delta E)$ can be directly determined by analyzing the DFT total energies. For example, the adsorption energy of $\mathrm{H}_{2} \mathrm{O}_{2}\left(E_{\text {ad }}\right)$ on substrate was defined as: $E_{\text {ad }}=E_{\text {substrate- } \mathrm{H}_{2} \mathrm{O}_{2}}-E_{\text {substrate }}-E_{\mathrm{H}_{2} \mathrm{O}_{2}}$ , where $E_{\text {substrate- } \mathrm{H}_{2} \mathrm{O}_{2}}, E_{\text {substrate }}$, and $E_{\mathrm{H}_{2} \mathrm{O}_{2}}$ are the DFT total energies for the $\mathrm{H}_{2} \mathrm{O}_{2}$ adsorbed substrate, free substrate, and $\mathrm{H}_{2} \mathrm{O}_{2}$ molecule, respectively. $\Delta E_{\mathrm{ZPE}}$ and $\Delta S$ are the zero point energy difference and the entropy difference between the adsorbed state and the gas phase, respectively, and $T$ is the system temperature (298.15 K, in our work). For each system, its $E_{\text {zpe }}$ can be calculated by summing vibrational frequencies over all normal modes $\nu\left(E_{\text {zpe }}=1 / 2 \Sigma \hbar \nu\right)$. The entropies of the free molecules $\left(\mathrm{H}_{2} \mathrm{O}_{2}, \mathrm{H}_{2}\right.$, and $\left.\mathrm{H}_{2} \mathrm{O}\right)$ were taken from the NIST database, while the energy contribution from the adsorbed state is neglected. One-half of the chemical potential of $\mathrm{H}_{2}$ molecule was used as the chemical potential of the proton-electron pairs. In addition, the conductor-like screening model (COSMO) was used to simulate the $\mathrm{H}_{2} \mathrm{O}$ solvent conditions, and its dielectric constant was 78.54 .

\section{Results and Discussion}

\subsection{Characterization of SA Co-MoS}

SA Co- $-\mathrm{MoS}_{2}$ was obtained via our recently developed assembly leaching method. The as-synthesized material had the form of ultrathin nanosheets with no Co nanoparticles or clusters on the surface (Fig. S1a), which was also further validated by XRD patterns (Fig. S1b). From the images of EDX, Co was uniformly distributed over the whole catalyst (Fig. S1c). More interestingly, the high-resolution TEM images showed that the introduction of Co atoms induced the crystal lattice of $\mathrm{MoS}_{2}$ from the well-organized to disordered arrangement (Fig. S2). Highly abundant single Co atoms were clearly observed by high-angle annular dark field scanning transmission electron microscopy (HAADFSTEM), as indicated by the bright spots marked by red arrows in Fig. 1a. The line profile from atomically sensitive electron energy loss spectroscopy (EELS) provided Co $\mathrm{L}_{2}$ and $\mathrm{L}_{3}$ edges of 794 and $779 \mathrm{eV}$, respectively (Fig. 1b) [35]. The XPS results of Co $2 p$ confirmed that the major state of $\mathrm{SA} \mathrm{Co}-\mathrm{MoS}_{2}$ was $\mathrm{Co}^{3+}$ (Fig. S3). The Fourier transform of the extended X-ray absorption fine structure (FT-EXAFS) analysis of SA Co-MoS 2 exhibited a strong peak at $1.79 \AA$ assigned to Co-S coordination (Fig. 1c and S4a) without $\mathrm{Co}-\mathrm{Co}$ bond contributions [36]. The formation of a $\mathrm{Co}-\mathrm{S}$ bond and lattice mismatch induced the phase change of $\mathrm{MoS}_{2}$ from the $2 \mathrm{H}$ phase to the distorted 1T phase, which was verified by the appearance of new vibration characteristic peaks of $1 \mathrm{~T}-\mathrm{MoS}_{2}$ in Raman spectra (Fig. S4b) [37]. Based on the quantitative EXAFS fitting analysis in $k$ and $R$ spaces (Fig. S5 and Table S1), the average Co-S coordination number within the $\mathrm{SA} \mathrm{Co}-\mathrm{MoS}_{2}$ is $3.4 \pm 0.6$ [38]. These results demonstrated the successful construction of a model SA Co- $-\mathrm{MoS}_{2}$ catalyst in which a single Co atom sat on top of the Mo atoms in 1T, and $\mathrm{MoS}_{2}$ was coordinated by three adjacent sulfur atoms (the inset of Fig. 1c) [39].

\subsection{The peroxidase-like Activity of SA Co- $-\mathrm{MoS}_{2}$}

The catalysis of the 3,3',5,5'-tetramethylbenzidine (TMB)$\mathrm{H}_{2} \mathrm{O}_{2}$ reaction system was assayed and optimized (Fig. S6) to evaluate the peroxidase-mimicking ability of SA $\mathrm{Co}-\mathrm{MoS}_{2}[29,40]$. The addition of SA Co- $\mathrm{MoS}_{2}$ resulted in a much stronger absorbance at $652 \mathrm{~nm}$ and yielded a more obvious blue color than the addition of pristine $\mathrm{MoS}_{2}$, as shown in Fig. 2a, b. The enhanced peroxidaselike activity of SA Co- $\mathrm{MoS}_{2}$ was further confirmed by the electrochemical response to the oxidation of TMB by $\mathrm{H}_{2} \mathrm{O}_{2}$ (Fig. S7) and proven with other chromogenic peroxidase substrates, $o$-phenylenediamine (OPD) (Fig. S8a) and 2,2'-azinobis(3-ethylbenzthiazoline-6-sulfonate) (ABTS) (Fig. S8b) [39]. The catalytic activity of SA Co- $-\mathrm{MoS}_{2}$ was dependent on the $\mathrm{pH}$, temperature, and $\mathrm{H}_{2} \mathrm{O}_{2}$ concentration but was less sensitive to these factors than was horseradish peroxidase (HRP) (Fig. S9). The typical Michaelis-Menten curves for $\mathrm{H}_{2} \mathrm{O}_{2}$ (Fig. S10a) and TMB (Fig. 

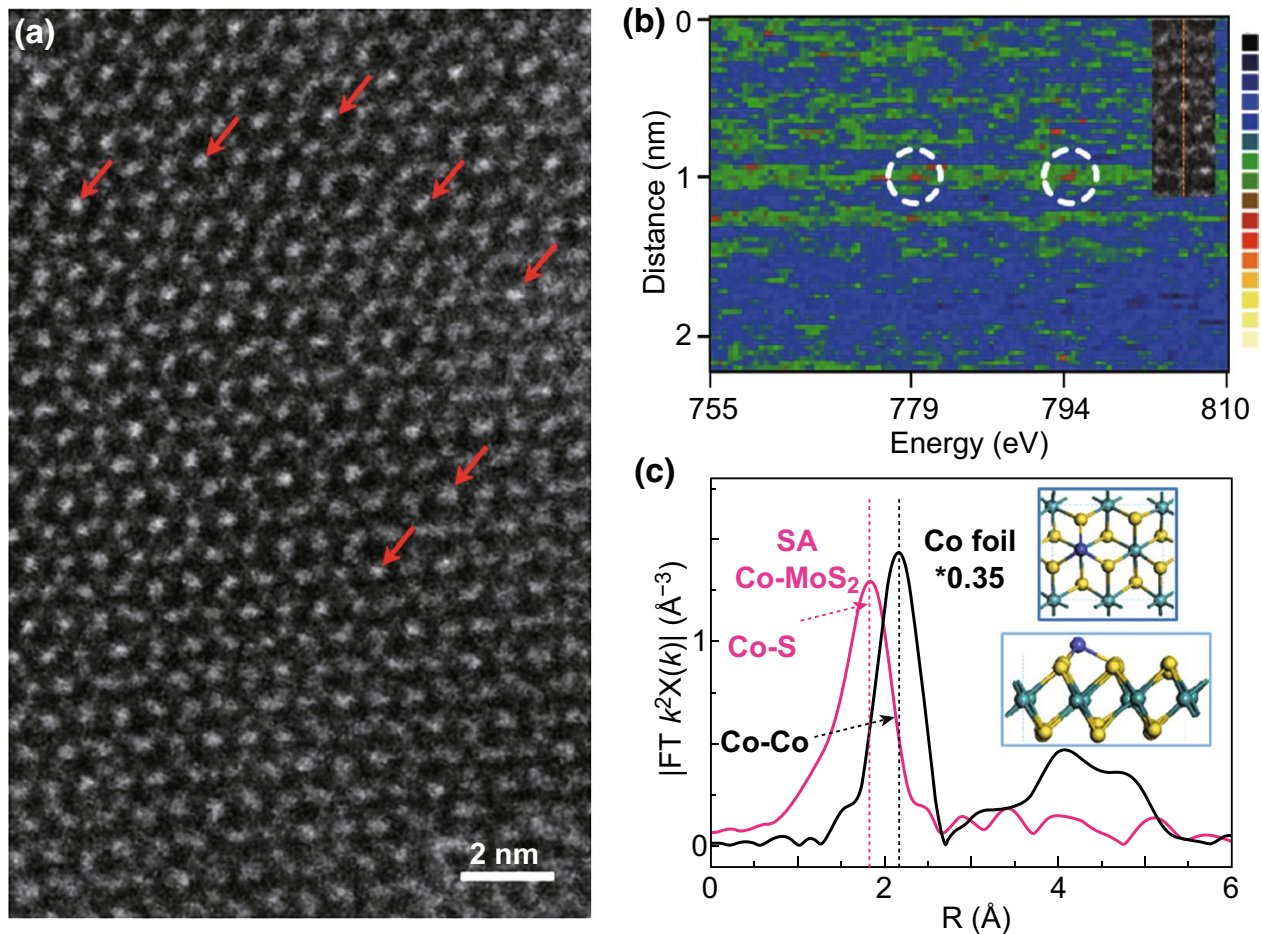

Fig. 1 a Aberration-corrected HAADF-STEM image of SA Co-MoS ${ }_{2}$. b EELS results of SA Co-MoS 2 . c FT-EXAFS spectra of SA Co-MoS 2 and cobalt foil at the Co K-edge. The inset shows the atomic structure of SA Co-MoS 2 . Yellow spheres: S; aqua spheres: Mo; slate blue spheres: Co. (Color figure online)

S10b) were measured and then fitted to Lineweaver-Burk plots, from which the apparent steady-state kinetic parameters were determined and compared with those of HRP (Table S2) [41]. The double-reciprocal plots obtained by varying the $\mathrm{H}_{2} \mathrm{O}_{2}$ concentration with a fixed concentration of TMB (Fig. S10c) or vice versa (Fig. S10d) showed nearly equal slopes, which was characteristic of a typical ping-pong mechanism, as was observed for HRP. All the above experimental results demonstrated that SA $\mathrm{Co}-\mathrm{MoS}_{2}$ could serve as a peroxidase mimic with high activity and stability. According to previous reports, the peroxidase mimic-mediated activity of $\mathrm{MoS}_{2}$ depended on the amount of hydroxyl radical $(\cdot \mathrm{OH})$ produced by the Fenton-like mechanism [42]. Therefore, terephthalic acid (TA) was used as a fluorescent probe to detect $\cdot \mathrm{OH}$ during the reaction, where TA easily captured $\cdot \mathrm{OH}$ and generated highly fluorescent 2-hydroxy terephthalic acid, which exhibited emission at approximately $425 \mathrm{~nm}$ [43] As shown in Fig. 2c, the fluorescence at $425 \mathrm{~nm}$ was remarkably enhanced by both $\mathrm{MoS}_{2}$ and SA Co- $-\mathrm{MoS}_{2}$, indicating that more $\cdot \mathrm{OH}$ was produced in the presence of the catalysts. However, the $\mathrm{MoS}_{2}$ system showed much stronger fluorescence than the SA Co- $-\mathrm{MoS}_{2}$ system, which was opposite the trend in the corresponding peroxidase-like performance shown in Fig. 2c. This phenomenon suggested that the increased catalytic activity of SA Co- $-\mathrm{MoS}_{2}$ toward $\mathrm{H}_{2} \mathrm{O}_{2}$ did not rely on the Fenton-like reaction [44, 45]. The fluorescence intensity gradually decreased as the concentration of SA Co- $\mathrm{MoS}_{2}$ continued to increase (Fig. 2d), which further indicated that the introduction of SA Co exhibited $\cdot \mathrm{OH}$ scavenging properties rather than generating $\cdot \mathrm{OH}$ [46-48].

To better understand the role played by SA Co in determining the catalytic efficiency, we explored the influence of thiocyanate ions $\left(\mathrm{SCN}^{-}\right)$on the peroxidase-like activity of SA Co- $\mathrm{MoS}_{2}$ because $\mathrm{SCN}^{-}$could form a stable chelate complex with metal-centered catalytic sites [49, 50]. Interestingly, an appreciable decrease in the catalytic activity was observed based on the changes in the UV-Vis absorbance at $652 \mathrm{~nm}$ (Fig. 3a) and the electrochemical response 

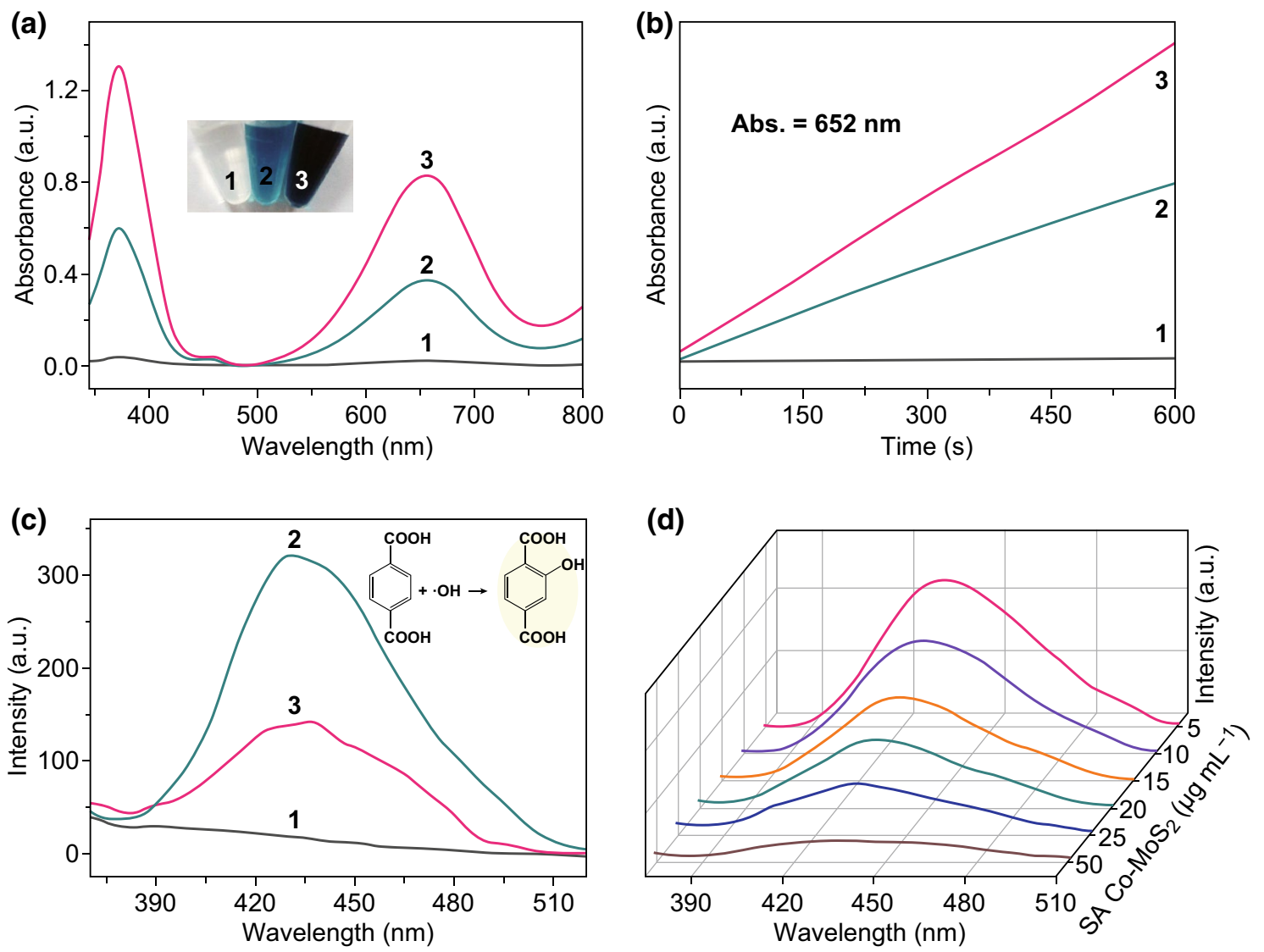

Fig. 2 a UV-Vis spectra of different reaction systems: (1) $\mathrm{TMB}+\mathrm{H}_{2} \mathrm{O}_{2}$, (2) $\mathrm{TMB}+\mathrm{H}_{2} \mathrm{O}_{2}+\mathrm{MoS}_{2}$, and (3) $\mathrm{TMB}+\mathrm{H}_{2} \mathrm{O}_{2}+\mathrm{SA} \mathrm{Co}-\mathrm{MoS}$. b The time-dependent absorbance changes at $652 \mathrm{~nm}$ and an optical image depicting the color changes. $\mathbf{c}$ The formation of $\cdot \mathrm{OH}$ using TA as a fluorescent probe in different reaction systems: (1) TA $+\mathrm{H}_{2} \mathrm{O}_{2}$, (2) TA $+\mathrm{H}_{2} \mathrm{O}_{2}+\mathrm{MoS}_{2}$, and (3) TA $+\mathrm{H}_{2} \mathrm{O}_{2}+\mathrm{SA}$ Co-MoS . d Effects of the concentration of SA Co- $\mathrm{MoS}_{2}$ on the changes in $\cdot \mathrm{OH}$ with $\mathrm{TA}$ as the fluorescence probe. (Color figure online)

(Fig. S11). Conversely, a significant enhancement in the fluorescence intensity at $425 \mathrm{~nm}$ was observed, as shown in Fig. 3b, indicating that more $\cdot \mathrm{OH}$ was generated in the system. The above phenomena demonstrated that SA Co was one of the major active centers responsible for the peroxidase-like activity. Blocking of SA Co caused more $\mathrm{H}_{2} \mathrm{O}_{2}$ to be decomposed by $\mathrm{MoS}_{2}$ than by the poisoned SA Co sites, as illustrated in Fig. 3c. This result further clarified that the introduction of SA Co did not enhance $\cdot \mathrm{OH}$ generation or decompose $\mathrm{H}_{2} \mathrm{O}_{2}$ by the Fenton reaction, and more investigations should be performed. Additionally, no obvious poisoning of the $\mathrm{MoS}_{2}$ catalyst by $\mathrm{SCN}^{-}$was observed (Fig. S12) due to the saturated coordination and low stability constant of molybdenum atoms. The other control experiments demonstrated that the peroxidase-like activity of SA $\mathrm{Co}-\mathrm{MoS}_{2}$ did not result from the effects of dissolved oxygen (Fig. S13a) or leached cobalt ions (Fig. S13b) [48].

\subsection{Mechanism of the Peroxidase-like Activity of SA $\mathrm{Co}-\mathrm{MoS}_{2}$}

The Michaelis-Menten constant $\left(K_{\mathrm{m}}\right)$ was calculated for the $\mathrm{MoS}_{2}$ and SA Co--MoS 2 catalysts toward different substrates (TMB and $\mathrm{H}_{2} \mathrm{O}_{2}$ ) based on the experimental results of a kinetic analysis (Fig. 4a). $K_{\mathrm{m}}$ is an indicator of the binding affinity between enzymes and substrates. A lower $K_{\mathrm{m}}$ value represents a stronger affinity and vice versa [51]. The apparent $K_{\mathrm{m}}$ value of $\mathrm{SA} \mathrm{Co}-\mathrm{MoS}_{2}$ with $\mathrm{H}_{2} \mathrm{O}_{2}$ was lower than that of $\mathrm{MoS}_{2}$ with $\mathrm{H}_{2} \mathrm{O}_{2}$. To explore the internal factors affecting this phenomenon, we also calculated the adsorption energies $\left(E_{\text {ads }}\right)$ of $\mathrm{H}_{2} \mathrm{O}_{2}$ and TMB on $\mathrm{MoS}_{2}$ and $\mathrm{SA} \mathrm{Co}-\mathrm{MoS}_{2}$ by means of density functional theory (DFT) computations. SA Co- $-\mathrm{MoS}_{2}$ possessed a higher affinity for $\mathrm{H}_{2} \mathrm{O}_{2}$, while $\mathrm{MoS}_{2}$ preferred to adsorb TMB, as shown in Fig. 4b, which is in good agreement with the trend of $K_{\mathrm{m}}$ values determined 

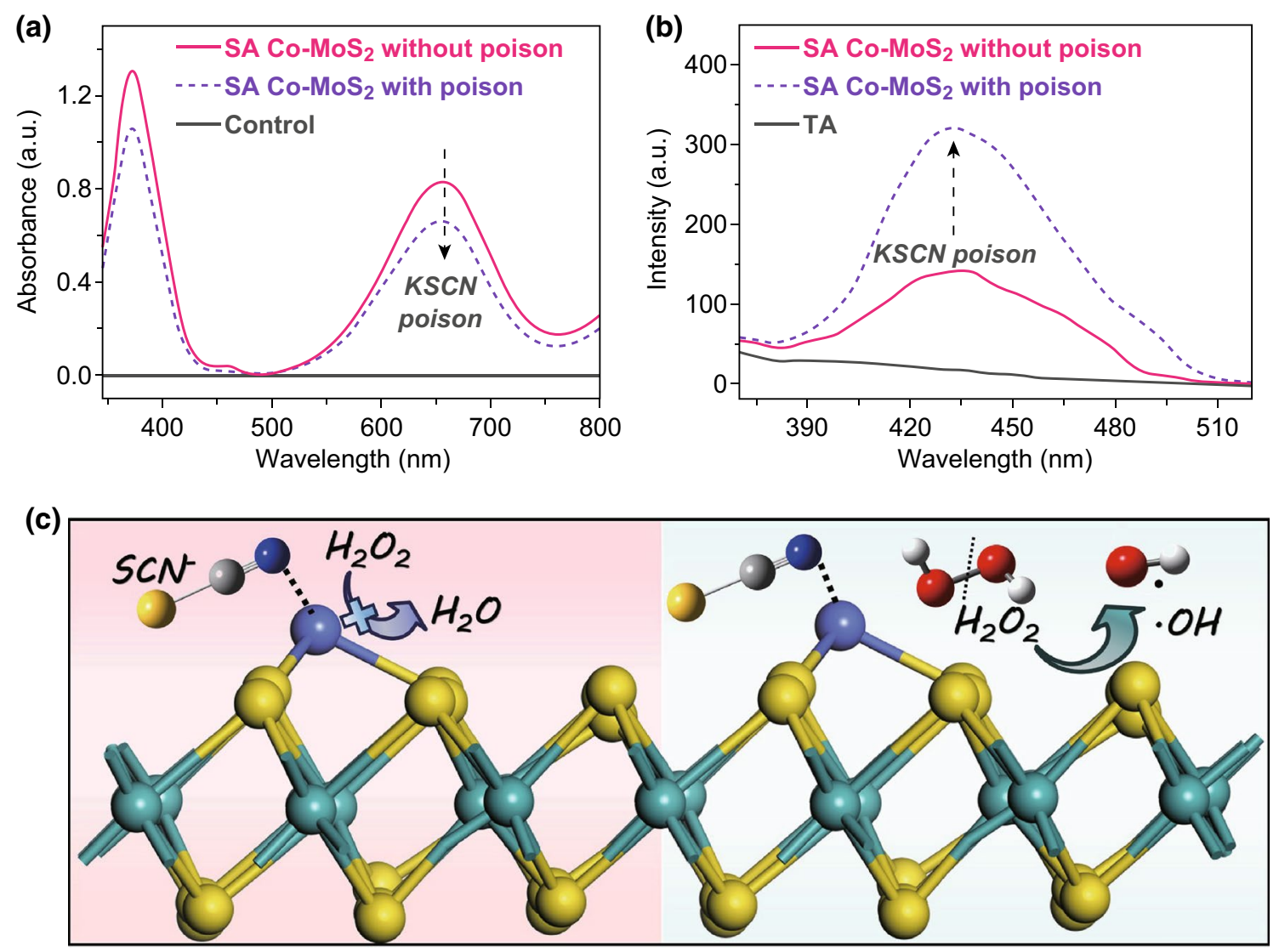

Fig. 3 Changes in the a UV-Vis spectrum and b fluorescence spectrum when SA Co-MoS 2 was poisoned with $10 \mathrm{mM}$ KSCN. c The corresponding illustration of the poison's influences. Red spheres: O; gray spheres: C; white spheres: H; light-blue spheres: N. (Color figure online)

by experiments. Moreover, $\mathrm{MoS}_{2}$ is negatively charged and prefers interactions with positively charged TMB by electrostatic adsorption [42]. These results also indicated that the $\mathrm{H}_{2} \mathrm{O}_{2}$ molecule could be weakly adsorbed on pristine $2 \mathrm{H}$ phase $\mathrm{MoS}_{2}$ monolayers, with an $E_{\text {ads }}$ of $-0.10 \mathrm{eV}$ (Fig. 4b). When considering $\Delta E_{\text {zpe }}$ and entropy, the $\Delta G$ of $\mathrm{H}_{2} \mathrm{O}_{2}$ adsorption on the $\mathrm{MoS}_{2}$ monolayers was $0.71 \mathrm{eV}$, indicating that the $\mathrm{H}_{2} \mathrm{O}_{2}$ molecule would easily escape from the surface. Thus, the $\mathrm{MoS}_{2}$ monolayers would exhibit poor catalytic performance in the peroxidase-like reaction. In contrast, the $\mathrm{H}_{2} \mathrm{O}_{2}$ molecule could be chemisorbed on SA $\mathrm{Co}-\mathrm{MoS}_{2}$ with an $E_{\text {ads }}$ value of $-1.09 \mathrm{eV}$ and a $\Delta G$ value of $-0.28 \mathrm{eV}$, which led to the formation of one $\mathrm{Co}-\mathrm{O}$ bond with a length of $1.95 \AA$ (Fig. 4b). The strong adsorption of the $\mathrm{H}_{2} \mathrm{O}_{2}$ molecule on SA Co- $\mathrm{MoS}_{2}$ could also be verified by the computed partial density of states (PDOSs, Fig. 4c), from which obvious hybridization between Co $3 \mathrm{~d}$ orbitals and $\mathrm{O} 2 \mathrm{p}$ orbitals can be observed. In addition, approximately 0.32 electrons were transferred from $\mathrm{H}_{2} \mathrm{O}_{2}$ molecules to the Co-anchored $\mathrm{MoS}_{2}$ monolayers, mainly accumulating in the $\mathrm{Co}-\mathrm{O}$ bond. Thus, $\mathrm{H}_{2} \mathrm{O}_{2}$ could be sufficiently activated by $\mathrm{SA} \mathrm{Co}-\mathrm{MoS}_{2}$ (Fig. 4d), facilitating the subsequent peroxidase-like reaction.

The different $E_{\text {ads }}$ values for $\mathrm{MoS}_{2}$ and SA Co- $\mathrm{MoS}_{2}$ were attributed to the different catalytic pathways in the peroxidase-like catalytic reaction. (1) Due to the stronger affinity toward $\mathrm{H}_{2} \mathrm{O}_{2}$ and the high redox potential of $\mathrm{Co}^{3+}$ / $\mathrm{Co}^{2+}(1.808 \mathrm{~V})$, we proposed that SA Co can serve as an electron transfer mediator. Cytochrome $c$ (cyt $c$ ) is an active electron transporter in biological oxidation, which can be used to verify the accepting electron capability of $\mathrm{SA} \mathrm{Co-} \mathrm{MoS}_{2}$. The two original UV-Vis absorption peaks at 520 and $550 \mathrm{~nm}$ attributed to cyt $c$ in a reduced state disappeared with the evolution of a new peak at $530 \mathrm{~nm}$ for the oxidized cyt $c$ after the addition of SA Co- $-\mathrm{MoS}_{2}$ without or with pure nitrogen for $0.5 \mathrm{~h}$. All these results indicated that $\mathrm{SA} \mathrm{Co-}-\mathrm{MoS}_{2}$ was able to obtain electrons from cyt $c$ and did not depend on dissolved oxygen (Fig. 

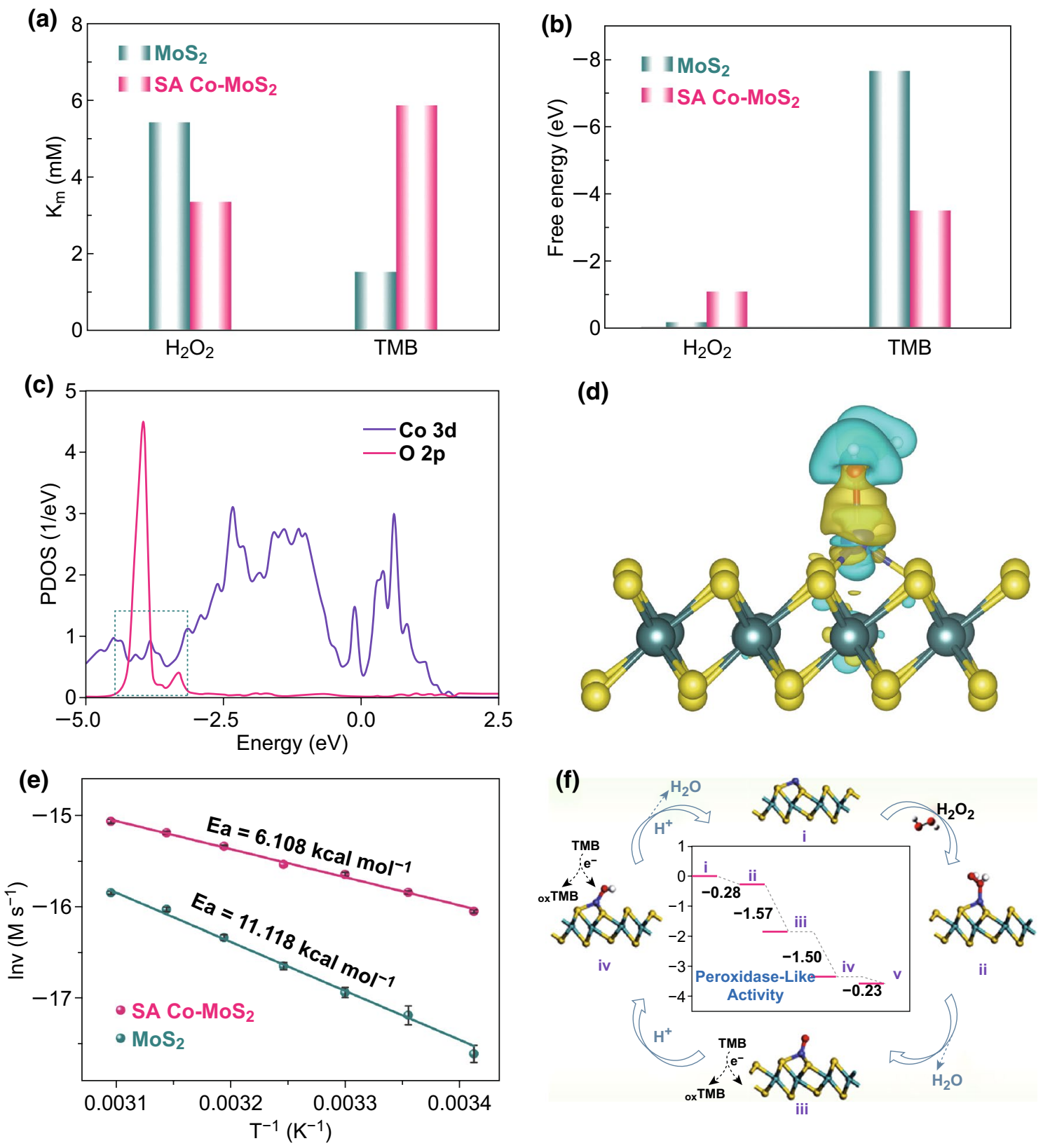

Fig. 4 a The experimental $K_{\mathrm{m}}$ values and b DFT-calculated adsorption energies of TMB and $\mathrm{H}_{2} \mathrm{O}_{2}$ on $\mathrm{MoS}_{2}$ and SA Co-MoS . c Theoretical PDOS calculated for $\mathrm{H}_{2} \mathrm{O}_{2}$ on SA Co- $\mathrm{MoS}_{2}$. d Charge density difference for $\mathrm{H}_{2} \mathrm{O}_{2}$ adsorption on the Co/MoS $\mathrm{Monolayer}_{2}$ Regions of electron accumulation and depletion are displayed in blue and yellow, respectively. The isosurface value is \pm 0.02 electrons/a.u. ${ }^{3}$. e Logarithmic reaction rate over $\mathrm{MoS}_{2}$ and SA Co-MoS 2 as a function of the reciprocal temperature. $\mathbf{f}$ DFT-calculated reaction energy diagram of $\mathrm{H}_{2} \mathrm{O}_{2}$ dissociation on $\mathrm{SA} \mathrm{Co}-\mathrm{MoS}_{2}$. (Color figure online)

S14) $[44,46,52]$. (2) The intrinsic enzyme-mimicking property of the $\mathrm{MoS}_{2}$ support may result from the occurrence of Fenton-like reactions because the support was more likely to attract TMB (Fig. 4a, b). The above conclusion provided further evidence to support the results of our fluorescence and poisoning experiments and our hypothesis, as shown in Fig. 3. Based on the logarithmic Arrhenius plots (Fig. 4e), the activation energies $\left(E_{a}\right)$ were calculated to be $11.12 \pm 0.51$ $\left(\mathrm{MoS}_{2}\right)$ and $6.11 \pm 0.67 \mathrm{kcal} \mathrm{mol}^{-1}\left(\mathrm{SA} \mathrm{Co}-\mathrm{MoS}_{2}\right)$. These 

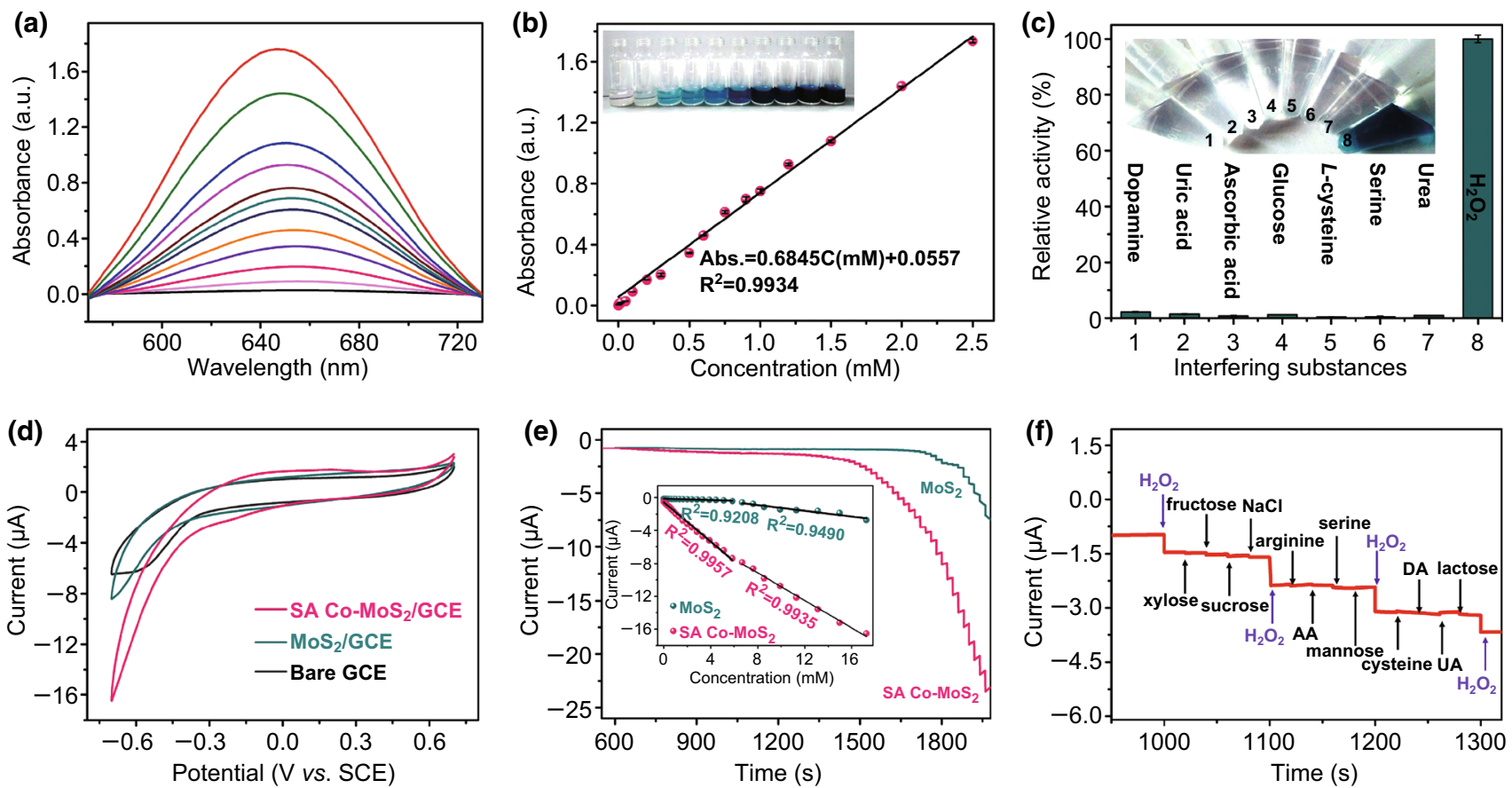

Fig. 5 a Changes in the UV-Vis absorbance spectra in the presence of different concentrations of $\mathrm{H}_{2} \mathrm{O}_{2}$. b The corresponding linear calibration plots. c The selectivity of the $\mathrm{SA} \mathrm{Co}-\mathrm{MoS}_{2}$ peroxidase-like catalytic activity. d CV responses of SA Co- $\mathrm{MoS}_{2} / \mathrm{GCE}, \mathrm{MoS} / \mathrm{GCE}$, and bare GCE in the presence of $0.1 \mathrm{mM} \mathrm{H}_{2} \mathrm{O}_{2}$ in $0.01 \mathrm{M} \mathrm{PBS}(\mathrm{pH}=7.4)$. e Amperometric response recorded at the $\mathrm{MoS}_{2} / \mathrm{GCE}$ and SA Co-MoS $/$ GCE after the successive addition of $\mathrm{H}_{2} \mathrm{O}_{2}$ to $0.01 \mathrm{M} \mathrm{PBS}(\mathrm{pH}=7.4)$ at $-0.50 \mathrm{~V}$. The inset is an enlargement of the low-concentration region (inset: the calibration curve of the $\mathrm{MoS}_{2} / \mathrm{GCE}$ and SA Co- $\mathrm{MoS}_{2} / \mathrm{GCE}$ as a function of the $\mathrm{H}_{2} \mathrm{O}_{2}$ concentration). $\mathbf{f}$ The selectivity of the SA Co-MoS 2 composite material

experimental results verified that SA Co- $\mathrm{MoS}_{2}$ effectively reduced the energy barrier. The free energy profile and the corresponding atomic configurations of various states are presented in Figs. $4 \mathrm{f}$ and S15. Our results indicated that the adsorbed $\mathrm{H}_{2} \mathrm{O}_{2}$ molecule dissociated into $\mathrm{O}^{*}$ species and one $\mathrm{H}_{2} \mathrm{O}$ molecule $[53,54]$. This process was downhill in the free energy profile by $1.57 \mathrm{eV}$. After the release of the formed $\mathrm{H}_{2} \mathrm{O}$ molecule, the remaining $\mathrm{O}$ atom, bound to the Co site with a Co-O length of $1.63 \AA$, reacted with one proton that originated from the TMB to form an $\mathrm{OH}$ species located at the Co site with a $\mathrm{Co}-\mathrm{O}$ bond of $1.76 \AA$. Remarkably, this hydrogenation process was exothermic, with a Gibbs energy value $(\Delta G)$ of $-1.50 \mathrm{eV}$. Finally, the adsorbed $\mathrm{OH}$ group reacted with one proton to form a second $\mathrm{H}_{2} \mathrm{O}$ molecule. This final step was also downhill in the free energy profile by $0.23 \mathrm{eV}$. Overall, each elementary step in the whole peroxidaselike reaction was exothermic in the free energy profile, suggesting the high catalytic activity of a single Co atom supported on the $\mathrm{MoS}_{2}$ monolayer. In addition, the $\mathrm{MoS}_{2}$ base of SA Co- $\mathrm{MoS}_{2}$ was converted from $2 \mathrm{H}$ phase to distorted $1 \mathrm{~T}$ phase, which also contributed to the catalytic efficiency improvement. As shown in Fig. S16a, b, the peroxidase-like activity of $\mathrm{MoS}_{2}$ was enhanced through the phase transformation from $2 \mathrm{H}$ to $1 \mathrm{~T}$ phase, which was confirmed by the UV-Vis spectra and electrochemical responses. The strengthened peroxidase-like catalytic activity of $1 \mathrm{~T}-\mathrm{MoS}_{2}$ was attributed to the improvement in conductivity (Fig. S16c) [55], the decrease in the Gibbs energies $(\Delta G)$, and the negative thermodynamic energy $(\Delta U)$ compared with the $2 \mathrm{H}-\mathrm{MoS}_{2}$ (Fig. S17). All of these intrinsic and unique characteristics contributed to the high-efficiency peroxidase-like activity of SA Co-MoS ${ }_{2}$.

\subsection{Application of the Peroxidase-like Activity of SA $\mathrm{Co}-\mathrm{MoS}_{2}$}

Sensitive and effective biosensors for colorimetric and electrochemical $\mathrm{H}_{2} \mathrm{O}_{2}$ determination were constructed on the basis of SA Co- $\mathrm{MoS}_{2}$ peroxidase-like nanozymes [56]. As 
presented in Fig. 5a, the intensity of the absorption spectra increased with the concentration of $\mathrm{H}_{2} \mathrm{O}_{2}$ with a satisfactory linear relationship ranging from $1 \mu \mathrm{M}$ to $2.5 \mathrm{mM}$ (Fig. 5b). This established colorimetric method also exhibited specific selectivity, good reproducibility, and high long-term storage stability for $\mathrm{H}_{2} \mathrm{O}_{2}$ (Figs. 5c and S18). In addition, the electrocatalytic activity of SA Co- $-\mathrm{MoS}_{2}$ toward $\mathrm{H}_{2} \mathrm{O}_{2}$ presented significantly enhanced $\mathrm{CV}$ responses (Fig. 5d). Compared with the relevant electrochemical $\mathrm{H}_{2} \mathrm{O}_{2}$ sensors (Table S3), the SA Co- $\mathrm{MoS}_{2}$-modified electrode possessed a more extended linear current response ranging from $50 \mathrm{nM}$ to $17.241 \mathrm{mM}$ (Fig. 5e) and a lower detection limit of $10 \mathrm{nM}$ (Fig. S19a) with high selectivity (Fig. 5f), good reproducibility, and stability (Fig. S19b-d). The high stability of SA $\mathrm{Co}-\mathrm{MoS}_{2}$ was confirmed by X-ray absorption fine structure (XAFS) analysis after the tests (Fig. S20), which indicated that $\mathrm{SA} \mathrm{Co-} \mathrm{MoS}_{2}$ could be used as an excellent enzyme mimic. The underlying source of the remarkable performance could be the balancing of interactions between the catalyst and reaction substrates upon the introduction of SA Co, which adhered to the Sabatier principle of heterogeneous biocatalysis quite well [41, 57].

\section{Conclusions}

In summary, we first demonstrated that $\mathrm{SA} \mathrm{Co}-\mathrm{MoS}_{2}$ is an excellent peroxidase mimic and revealed the occurrence of different mechanisms between the single-atom metal center and support, which provided a complementary strategy for achieving synergistic peroxidase-like properties. This work will not only open the door to another practical frontier of SACs but also offer an important new strategy for designing hybrid nanozymes for biocatalysis.

Acknowledgements This work was financially supported by the National Key Research and Development Program of China (No. 2016YFA0200400), the Jilin Province Science and Technology Development Program (No. 20190201233JC), the National Natural Science Foundation of China (Nos. 51571100 and 51872116), the Natural Science Funds for Distinguished Young Scholars of Heilongjiang Province (No. JC2018004), the Excellent Young Foundation of Harbin Normal University (No. XKYQ201304), the National Postdoctoral Program for Innovative Talents (BX20180117), the Program for JLU Science and Technology Innovative Research Team (JLUSTIRT, 2017TD-09), and the Fundamental Research Funds for the Central Universities.
Open Access This article is distributed under the terms of the Creative Commons Attribution 4.0 International License (http:// creativecommons.org/licenses/by/4.0/), which permits unrestricted use, distribution, and reproduction in any medium, provided you give appropriate credit to the original author(s) and the source, provide a link to the Creative Commons license, and indicate if changes were made.

Electronic supplementary material The online version of this article (https://doi.org/10.1007/s40820-019-0324-7) contains supplementary material, which is available to authorized users.

\section{References}

1. M. Garcia-Viloca, J.L. Gao, M. Karplus, D.G. Truhlar, How enzymes work: analysis by modern rate theory and computer simulations. Science 303(5655), 186-195 (2004). https://doi. org/10.1126/science. 1088172

2. H. Wei, E.K. Wang, Nanomaterials with enzyme-like characteristics (nanozymes): next-generation artificial enzymes. Chem. Soc. Rev. 42(14), 6060-6093 (2013). https://doi. org/10.1039/C3CS35486E

3. X.F. Yang, A.Q. Wang, B.T. Qiao, J. Li, J.Y. Liu, T. Zhang, Single-atom catalysts: a new frontier in heterogeneous catalysis. Acc. Chem. Res. 46(8), 1740-1748 (2013). https://doi. org/10.1021/ar300361m

4. J.J. Wu, X.Y. Wang, Q. Wang, Z.P. Lou, S. Li, Y.Y. Zhu, L. Qin, H. Wei, Nanomaterials with enzyme-like characteristics (nanozymes): next-generation artificial enzymes (II). Chem. Soc. Rev. 48(4), 1004-1076 (2019). https://doi.org/10.1039/ C8CS00457A

5. D. Jiang, D. Ni, Z.T. Rosenkrans, P. Huang, X. Yan, W. Cai, Nanozyme: new horizons for responsive biomedical applications. Chem. Soc. Rev. (2019). https://doi.org/10.1039/C8CS0 $0718 \mathrm{G}$

6. M.A. Komkova, E.E. Karyakina, A.A. Karyakin, Catalytically synthesized prussian blue nanoparticles defeating natural enzyme peroxidase. J. Am. Chem. Soc. 140(36), 11302-11307 (2018). https://doi.org/10.1021/jacs.8b05223

7. H. Wang, K.W. Wan, X.H. Shi, Recent advances in nanozyme research. Adv. Mater. (2018). https://doi.org/10.1002/ adma.201805368

8. J.N. Li, W.Q. Liu, X.C. Wu, X.F. Gao, Mechanism of pHswitchable peroxidase and catalase-like activities of gold, silver, platinum and palladium. Biomaterials 48, 37-44 (2015). https://doi.org/10.1016/j.biomaterials.2015.01.012

9. G. Fang, W.F. Li, X.M. Shen, J.M. Perez-Aguilar, Y. Chong et al., Differential Pd-nanocrystal facets demonstrate distinct antibacterial activity against gram-positive and gramnegative bacteria. Nat. Commun. 9(1), 129 (2018). https:// doi.org/10.1038/s41467-017-02502-3

10. Y. Chong, X. Dai, G. Fang, R.F. Wu, L. Zhao et al., Palladium concave nanocrystals with high-index facets accelerate 
ascorbate oxidation in cancer treatment. Nat. Commun. 9(1), 4861 (2018). https://doi.org/10.1038/s41467-018-07257-z

11. S. Ghosh, P. Roy, N. Karmodak, E.D. Jemmis, G. Mugesh, Nanoisozymes: crystal-facet-dependent enzyme-mimetic activity of $\mathrm{V}_{2} \mathrm{O}_{5}$ nanomaterials. Angew. Chem. 130(17), 4600-4605 (2018). https://doi.org/10.1002/ange.201800681

12. H. Wang, P.H. Li, D.Q. Yu, Y. Zhang, Z.Z. Wang et al., Unraveling the enzymatic activity of oxygenated carbon nanotubes and their application in the treatment of bacterial infections. Nano Lett. 18(6), 3344-3351 (2018). https ://doi.org/10.1021/acs.nanolett.7b05095

13. H.J. Sun, Y. Zhou, J.S. Ren, X.G. Qu, Carbon nanozymes: enzymatic properties, catalytic mechanism, and applications. Angew. Chem. Int. Ed. 57(30), 9224-9237 (2018). https:// doi.org/10.1002/anie.201712469

14. L. Han, H.J. Zhang, D.Y. Chen, F. Li, Protein-directed metal oxide nanoflakes with tandem enzyme-like characteristics: Colorimetric glucose sensing based on one-pot enzymefree cascade catalysis. Adv. Funct. Mater. 28(17), 1800018 (2018). https://doi.org/10.1002/adfm.201800018

15. P. Zhang, D. Sun, A. Cho, S. Weon, S. Lee et al., Modified carbon nitride nanozyme as bifunctional glucose oxidase-peroxidase for metal-free bioinspired cascade photocatalysis. Nat. Commun. 10(1), 940 (2019). https://doi. org/10.1038/s41467-019-08731-y

16. N.C. Veitch, Horseradish peroxidase: a modern view of a classic enzyme. Phytochemistry 65(3), 249-259 (2004). https://doi.org/10.1016/j.phytochem.2003.10.022

17. X.J. Cui, W. Li, P. Ryabchuk, K. Junge, M. Beller, Bridging homogeneous and heterogeneous catalysis by heterogeneous single-metal-site catalysts. Nat. Catal. 1(6), 385-397 (2018). https://doi.org/10.1038/s41929-018-0090-9

18. A.Q. Wang, J. Li, T. Zhang, Heterogeneous single-atom catalysis. Nat. Rev. Chem. 2(6), 65-81 (2018). https://doi. org/10.1038/s41570-018-0010-1

19. Y. Wang, J. Mao, X.G. Meng, L. Yu, D.H. Deng, X.H. Bao, Catalysis with two-dimensional materials confining single atoms: concept, design, and applications. Chem. Rev. 119(3), 1806-1854 (2019). https://doi.org/10.1021/acs. chemrev.8b00501

20. L. Huang, J. Chen, L. Gan, J. Wang, S. Dong, Single-atom nanozymes. Sci. Adv. 5(5), eaav5490 (2019). https://doi. org/10.1126/sciadv.aav5490

21. C. Zhao, C. Xiong, X.K. Liu, M. Qiao, Z.J. Li et al., Unraveling the enzyme-like activity of heterogeneous single atom catalyst. Chem. Commun. 55(16), 2285-2288 (2019). https ://doi.org/10.1039/c9cc00199a

22. B.L. Xu, H. Wang, W.W. Wang, L.Z. Gao, S.S. Li et al., Single-atom nanozyme for wound antibacterial applications. Angew. Chem. Int. Ed. 58(15), 4911-4916 (2019). https:// doi.org/10.1002/anie.201813994

23. Y. Wang, Z. Zhang, G. Jia, L. Zheng, J. Zhao, X. Cui, Elucidating the mechanism of the structure-dependent enzymatic activity of fe-n/c oxidase mimics. Chem. Commun. 55(36), 5271-5274 (2019). https://doi.org/10.1039/C9CC01503E
24. M. Huo, L. Wang, Y. Wang, Y. Chen, J. Shi, Nanocatalytic tumor therapy by single-atom catalysts. ACS Nano 13(2), 2643-2653 (2019). https://doi.org/10.1021/acsnano.9b00457

25. L. Jiao, H. Yan, Y. Wu, W. Gu, C. Zhu, D. Du, Y. Lin, When nanozymes meet single-atom catalysis. Angew. Chem. Int. Ed. (Accepted Article, 2019). https://doi.org/10.1002/anie.20190 5645

26. J. Xie, H. Zhang, S. Li, R. Wang, X. Sun et al., Defect-rich $\mathrm{MoS}_{2}$ ultrathin nanosheets with additional active edge sites for enhanced electrocatalytic hydrogen evolution. Adv. Mater. 25(40), 5807-5813 (2013). https://doi.org/10.1002/ adma.201302685

27. C.T. Black, C.B. Murray, R.L. Sandstrom, S. Sun, Spindependent tunneling in self-assembled cobalt-nanocrystal superlattices. Science 290(5494), 1131-1134 (2000). https:// doi.org/10.1126/science.290.5494.1131

28. K. Qi, X.Q. Cui, L. Gu, S.S. Yu, X.F. Fan et al., Single-atom cobalt array bound to distorted $1 \mathrm{~T}-\mathrm{MoS}_{2}$ with ensemble effect for hydrogen evolution catalysis. Nat. Commun. (2019). https ://doi.org/10.1038/s41467-019-12997-7

29. B. Jiang, D.M. Duan, L.Z. Gao, M.J. Zhou, K.L. Fan et al., Standardized assays for determining the catalytic activity and kinetics of peroxidase-like nanozymes. Nat. Protoc. 13(7), 1506-1520 (2018). https://doi.org/10.1038/s41596-018-0001-1

30. B. Delley, An all-electron numerical method for solving the local density functional for polyatomic molecules. J. Chem. Phys. 92(1), 508-517 (1990). https://doi.org/10.1063/1.45845 2

31. B. Delley, From molecules to solids with the $\mathrm{DMol}^{3}$ approach. J. Chem. Phys. 113(18), 7756-7764 (2000). https://doi. org/10.1063/1.1316015

32. J.P. Perdew, K. Burke, M. Ernzerhof, Generalized gradient approximation made simple. Phys. Rev. Lett. 77(18), 38653868 (1996). https://doi.org/10.1103/PhysRevLett.77.3865

33. S. Grimme, Semiempirical gga-type density functional constructed with a long-range dispersion correction. J. Comput. Chem. 27(15), 1787-1799 (2006). https://doi.org/10.1002/ jcc. 20495

34. B. Delley, Hardness conserving semilocal pseudopotentials. Phys. Rev. B 66(15), 155125 (2002). https://doi.org/10.1103/ PhysRevB.66.155125

35. X.X. Wang, D.A. Cullen, Y.T. Pan, S. Hwang, M.Y. Wang et al., Nitrogen-coordinated single cobalt atom catalysts for oxygen reduction in proton exchange membrane fuel cells. Adv. Mater. 30(11), 1706758 (2018). https://doi.org/10.1002/ adma.201706758

36. N. Kornienko, J. Resasco, N. Becknell, C.M. Jiang, Y.S. Liu et al., Operando spectroscopic analysis of an amorphous cobalt sulfide hydrogen evolution electrocatalyst. J. Am. Chem. Soc. 137(23), 7448-7455 (2015). https://doi.org/10.1021/ jacs.5b03545

37. X. Fan, P. Xu, D. Zhou, Y. Sun, Y.C. Li, M.A.T. Nguyen, M. Terrones, T.E. Mallouk, Fast and efficient preparation of exfoliated $2 \mathrm{H} \mathrm{MoS}_{2}$ nanosheets by sonication-assisted lithium intercalation and infrared laser-induced $1 \mathrm{~T}$ to $2 \mathrm{H}$ phase 
reversion. Nano Lett. 15(9), 5956-5960 (2015). https://doi. org/10.1021/acs.nanolett.5b02091

38. Y. Wang, X.Q. Cui, J.X. Zhao, G.R. Jia, L. Gu et al., Rational design of $\mathrm{Fe}-\mathrm{N} / \mathrm{C}$ hybrid for enhanced nitrogen reduction electrocatalysis under ambient conditions in aqueous solution. ACS Catal. 9(1), 336-344 (2019). https://doi.org/10.1021/ acscatal.8b03802

39. G.L. Liu, A.W. Robertson, M.M.-J. Li, W.C.H. Kuo, M.T. Darby et al., $\mathrm{MoS}_{2}$ monolayer catalyst doped with isolated Co atoms for the hydrodeoxygenation reaction. Nat. Chem. 9, 810-816 (2017). https://doi.org/10.1038/nchem.2740

40. L. Jiao, L. Zhang, W. Du, H. Li, D. Yang, C. Zhu, Hierarchical manganese dioxide nanoflowers enable accurate ratiometric fluorescence enzyme-linked immunosorbent assay. Nanoscale 10(46), 21893-21897 (2018). https://doi.org/10.1039/C8NR0 $7096 \mathrm{~B}$

41. X.H. Xia, J.T. Zhang, N. Lu, M.J. Kim, K. Ghale et al., Pd-ir core-shell nanocubes: a type of highly efficient and versatile peroxidase mimic. ACS Nano 9(10), 9994-10004 (2015). https ://doi.org/10.1021/acsnano.5b03525

42. N.R. Nirala, S. Pandey, A. Bansal, V.K. Singh, B. Mukherjee, P.S. Saxena, A. Srivastava, Different shades of cholesterol: gold nanoparticles supported on $\mathrm{MoS}_{2}$ nanoribbons for enhanced colorimetric sensing of free cholesterol. Biosens. Bioelectron. 74, 207-213 (2015). https://doi.org/10.1016/j. bios.2015.06.043

43. K.-I. Ishibashi, A. Fujishima, T. Watanabe, K. Hashimoto, Quantum yields of active oxidative species formed on $\mathrm{TiO}_{2}$ photocatalyst. J. Photochem. Photobiol. A 134(1), 139-142 (2000). https://doi.org/10.1016/S1010-6030(00)00264-1

44. J.L. Dong, L.N. Song, J.J. Yin, W.W. He, Y.H. Wu, N. Gu, Y. Zhang, $\mathrm{Co}_{3} \mathrm{O}_{4}$ nanoparticles with multi-enzyme activities and their application in immunohistochemical assay. ACS Appl. Mater. Interfaces 6(3), 1959-1970 (2014). https://doi. org/10.1021/am405009f

45. H.M. Jia, D.F. Yang, X.N. Han, J.H. Cai, H.Y. Liu, W.W. He, Peroxidase-like activity of the $\mathrm{Co}_{3} \mathrm{O}_{4}$ nanoparticles used for biodetection and evaluation of antioxidant behavior. Nanoscale 8(11), 5938-5945 (2016). https://doi.org/10.1039/C6NR0 0860G

46. W.Y. Li, J.Y. Wang, J.C. Zhu, Y.Q. Zheng, $\mathrm{Co}_{3} \mathrm{O}_{4}$ nanocrystals as an efficient catalase mimic for the colorimetric detection of glutathione. J. Mater. Chem. B 6(42), 6858-6864 (2018). https ://doi.org/10.1039/C8TB01948G

47. Q.Q. Wang, L.L. Zhang, C.S. Shang, Z.Q. Zhang, S.J. Dong, Triple-enzyme mimetic activity of nickel-palladium hollow nanoparticles and their application in colorimetric biosensing of glucose. Chem. Commun. 52(31), 5410-5413 (2016). https ://doi.org/10.1039/C6CC00194G

48. J.S. Mu, Y. Wang, M. Zhao, L. Zhang, Intrinsic peroxidaselike activity and catalase-like activity of $\mathrm{Co}_{3} \mathrm{O}_{4}$ nanoparticles. Chem. Commun. 48(19), 2540-2542 (2012). https://doi. org/10.1039/C2CC17013B

49. M.S. Thorum, J.M. Hankett, A.A. Gewirth, Poisoning the oxygen reduction reaction on carbon-supported $\mathrm{Fe}$ and $\mathrm{Cu}$ electrocatalysts: evidence for metal-centered activity. J. Phys. Chem. Lett. 2(4), 295-298 (2011). https://doi.org/10.1021/jz1016284

50. Q. Wang, Z.Y. Zhou, Y.J. Lai, Y. You, J.G. Liu et al., Phenylenediamine based $\mathrm{FeN}_{x} / \mathrm{C}$ catalyst with high activity for oxygen reduction in acid medium and its active-site probing. J. Am. Chem. Soc. 136(31), 10882-10885 (2014). https://doi. org/10.1021/ja505777v

51. H. Lineweaver, D. Burk, The determination of enzyme dissociation constants. J. Am. Chem. Soc. 56(3), 658-666 (1934). https://doi.org/10.1021/ja01318a036

52. S.S. Fan, M.G. Zhao, L.J. Ding, H. Li, S.G. Chen, Preparation of $\mathrm{Co}_{3} \mathrm{O}_{4}$ /crumpled graphene microsphere as peroxidase mimetic for colorimetric assay of ascorbic acid. Biosens. Bioelectron. 89, 846-852 (2017). https://doi.org/10.1016/j. bios.2016.09.108

53. C. Zhao, C. Xiong, X. Liu, M. Qiao, Z. Li et al., Unraveling the enzyme-like activity of heterogeneous single atom catalyst. Chem. Commun. 55(16), 2285-2288 (2019). https://doi. org/10.1039/C9CC00199A

54. Y. Hu, X.J. Gao, Y. Zhu, F. Muhammad, S. Tan et al., Nitrogen-doped carbon nanomaterials as highly active and specific peroxidase mimics. Chem. Mater. 30(18), 6431-6439 (2018). https://doi.org/10.1021/acs.chemmater.8b02726

55. M.A. Lukowski, A.S. Daniel, F. Meng, A. Forticaux, L. Li, S. Jin, Enhanced hydrogen evolution catalysis from chemically exfoliated metallic $\mathrm{MoS}_{2}$ nanosheets. J. Am. Chem. Soc. 135(28), 10274-10277 (2013). https://doi.org/10.1021/ja404 $523 \mathrm{~s}$

56. L. Jiao, W. Xu, H. Yan, Y. Wu, W. Gu, H. Li, D. Du, Y. Lin, C. Zhu, A dopamine-induced Au hydrogel nanozyme for enhanced biomimetic catalysis. Chem. Commun. 55(66), 9865-9868 (2019). https://doi.org/10.1039/C9CC04436A

57. A.A. Balandin, in Modern State of the Multiplet Theory of Heterogeneous Catalysis. The paper was prepared for publication by e.I. Klabunovskii, ed. by D.D. Eley, H. Pines, P.B. Weisz (Academic Press; 1969), pp. 1-210 